\title{
ANALISIS SETTING DAN KOORDINASI RELE JARAK SALURAN 150 KV UNGARAN - KRAPYAK - SRONDOL
}

\author{
Andhika Rizki Priambodo*), Tejo Sukmadi, dan Mochammad Facta \\ Departemen Teknik Elektro, Universitas Diponegoro \\ Jl. Prof. Sudharto, SH, Kampus UNDIP Tembalang, Semarang 50275, Indonesia \\ ${ }^{*}$ E-mail: andhika.super@gmail.com
}

\begin{abstract}
Abstrak
Saluran transmisi merupakan salah satu komponen utama dalam penyaluran tenaga listrik. Pada saluran transmisi biasanya menggunakan rele jarak sebagai peralatan proteksi utamanya. Penelitian ini bertujuan untuk melakukan analisis setting dan koordinasi rele jarak pada saluran 150kV Ungaran - Krapyak - Srondol. Pada penelitian ini, data yang didapatkan dari PT.PLN digunakan untuk mensimulasikan setting rele jarak kondisi eksisting menggunakan software DigSILENT. Kemudian dilakukan perbandingan dengan standar dari NPAG Alstom mengenai rele jarak. Hasil simulasi menunjukkan bahwa setting rele jarak saluran $150 \mathrm{kV}$ Ungaran - krapyak - Srondol belum sesuai dengan standar. Jangkauan zona 1 rele jarak Srondol - Krapyak sebesar 80,14\% dan rele jarak Ungaran - Krapyak sebesar 83,25\%, sedangkan berdasarkan standar seharusnya jangkauan zona 1 rele sebesar $85 \%$ dari saluran. Setelah dilakukan perhitungan ulang setting rele, jangkauan zona 1 rele jarak Srondol - Krapyak dan rele jarak Ungaran - Krapyak menjadi 85\%, sehingga rele bekerja sesuai dengan standar yang dijadikan referensi
\end{abstract}

Kata kunci: sistem proteksi, saluran transmisi, rele jarak, DigSILENT

\begin{abstract}
Transmission line is one of the main components in the delivery of electric power. Transmission line usually is protected by a distance relay as the main protection device. This research is intended to analyze the setting and coordination of distance relay on 150kV Ungaran - Krapyak - Srondol transmission lines. In this study, data obtained from PT.PLN is used to simulate the existing distance relay settings using DigSILENT software. The setting is compared with NPAG Alstom about guide for protective relay applications to the Transmission Line. The simulation results show that the setting of Ungaran - Krapyak - Srondol distance relay does not meet with the standard. The range of zone 1 Srondol - Krapyak distance relay is $80.14 \%$ and the Ungaran - Krapyak distance relay is $83.25 \%$, while according to the standard zone 1 must be $85 \%$ of the channel. After re-calculation of the relay setting, the range of zone 1 Srondol - Krapyak and Ungaran - Krapyak distance relay becomes $85 \%$, so the distance relay is accomply to referred the standard.
\end{abstract}

Keywords: protection system, transmisson channel, distance relay,DigSILENT

\section{Pendahuluan}

Sistem tenaga listrik terdiri dari tiga bagian utama, yaitu pusat pembangkit listrik, saluran transmisi, dan sistem distribusi. Apabila terjadi gangguan pada saluran transmisi, maka sistem tenaga listrik tidak dapat berfungsi [1]. Oleh karena itu, diperlukan peralatan proteksi untuk melindungi saluran transmisi dari gangguan. Salah satunya adalah rele jarak [2]. Rele jarak digunakan untuk menetralisir dan mengetahui letak gangguan. Rele jarak menghitung impedansi saluran dengan membandingkan tegangan dan arus dengan menggunakan trafo tegangan dan trafo arus pada lokasi rele.

Simulasi perlu dilakukan untuk melihat koordinasi dan kinerja rele jarak pada masing - masing gardu induk. Selain itu simulasi dapat mengetahui apakah rele jarak sudah sesuai dengan standar yang ditetapkan oleh NPAG untuk mendapatkan kinerja dan koordinasi rele yang terbaik. Pada saluran udara tegangan menengah $150 \mathrm{kV}$ di area APP Semarang, setting rele hanya dilakukan dengan perhitungan manual menggunakan MathCAD dan diimplementasikan langsung pada rele yang akan disetting tanpa simulasi terlebih dahulu,

Penelitian yang telah dilakukan sebelumnya hanya dilakukan perhitungan dan analisis kinerja rele jarak pada subsistem 150kV secara manual [3] [4] [5]. Sedangkan penelitian yang lain [6], mensimulasikan rele jarak pada GI Pandean Lamper - Srondol - Krapyak secara satu arah menggunakan software DigSILENT PowerFactory 14.0

Pada penelitian ini dilakukan analisis setting dan koordinasi rele jarak pada saluran udara $150 \mathrm{kV}$ Ungaran - 
Krapyak - Srondol secara dua arah menggunakan software DigSILENT. Data setting rele jarak kondisi eksisting saluran Ungaran - Krapyak - Srondol didapatkan dari PT. PLN. Kemudian dilakukan analisis setting dan koordinasi rele jarak dengan cara membuat skenario gangguan pada saluran. Skenario gangguan dibuat berdasarkan data anomali yang didapatkan dari APP Semarang. Gangguan yang disimulasikan yaitu gangguan 3 fasa, 2 fasa, 1 fasa ke tanah, dan 2 fasa ke tanah. Kemudian dari hasil simulasi dapat dilihat apakah setting kondisi eksisting telah sesuai dengan standar dari NPAG Alstom. Berdasarkan hasil simulasi yang telah dilakukan menunjukkan bahwa setting kondisi eksisting pada saluran Ungaran - Krapyak Srondol belum memenuhi standar yang ditetapkan oleh NPAG tentang pengaturan zona proteksi rele jarak. Kemudian dilakukan perhitungan ulang menggunakan standar dari NPAG. Nilai setting hasil perhitungan ulang disimulasikan menggunakan Software DigSILENT PowerFactory 15.0 kemudian dilakukan analisis setting dan koordinasi rele. Setelah itu, dilakukan perbandingan antara setting rele kondisi eksisting dengan setting rele hasil resetting.

\section{Metode}

\subsection{Langkah Penelitian}

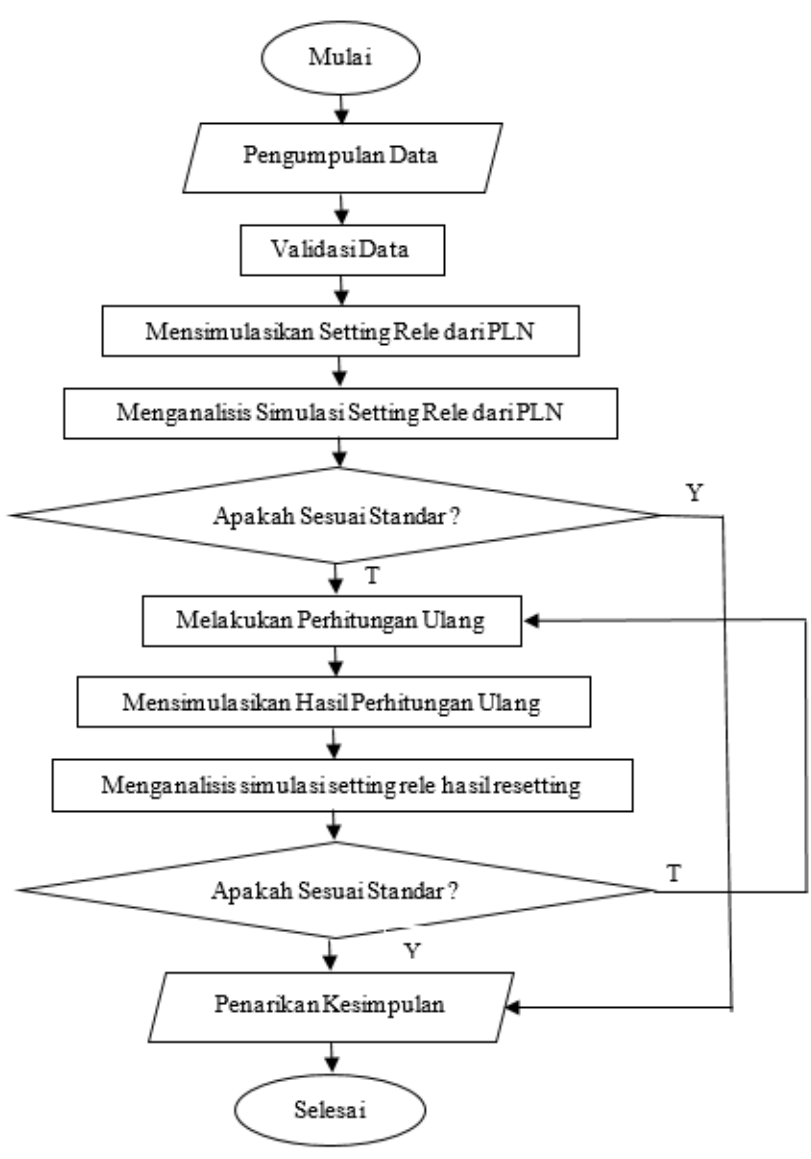

\subsection{Data Penelitian}

Data yang diperoleh berupa data single line diagram dalam bentuk file project digsilent, setting impedansi rele jarak, data penghantar, data impedansi trafo, data peralatan proteksi dan data anomali pada saluran Ungaran - Krapyak - Srondol yang didapatkan dari PT. PLN. Gambar 2. merupakan gambaran dari subsistem Ungaran - Krapyak Srondol. Gambar 3 merupakan gambaran zona proteksi rele jarak yang akan dianalisis.

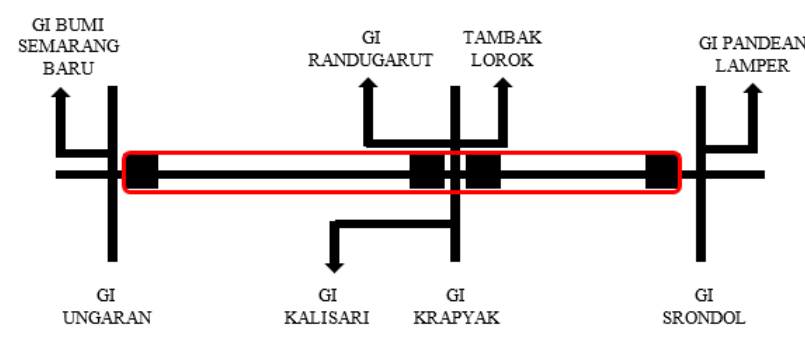

Gambar 2. Gambaran Subsistem

Gambar 2. merupakan gambaran subsistem Ungaran Krapyak - Srondol. Garis merah menggambarkan daerah yang akan dianalisis.

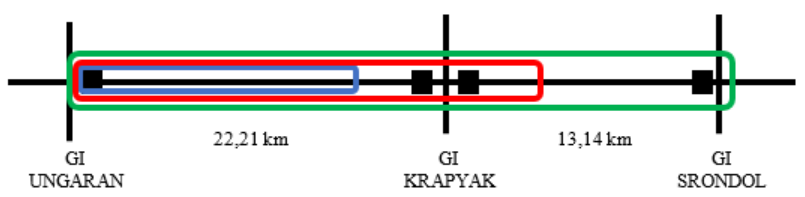

a. Rele Ungaran - Krapyak

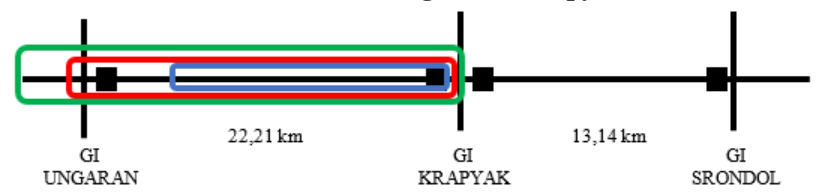

b. Rele Krapyak - Ungaran

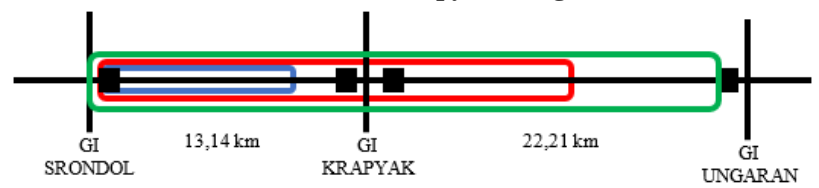

C. Rele Srondol - Krapyak

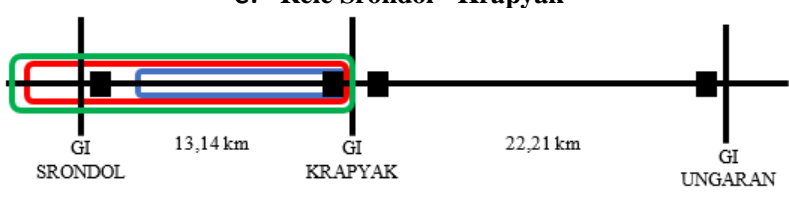

d. Rele Krapyak - Srondol

Gambar 3. Zona Proteksi Rele

Gambar 3. merupakan ilustrasi zona proteksi masing masing rele yang akan dianalisis. Zona 1 rele diilustrasikan garis biru, zona 2 rele diwakili garis merah, dan zona 3 rele diwakili garis hijau.

Gambar 1. Diagram Alir Penelitian 
Tabel 1. merupakan setting rele jarak pada subsistem Ungaran - Krapyak - Srondol.

Tabel 1. Setting Rele Jarak

\begin{tabular}{cccc}
\hline Saluran & Zona & $\mathbf{Z}(\mathbf{\Omega})$ & Jangkauan ( \%) \\
\hline \multirow{3}{*}{ Ungaran - Krapyak } & Zona 1 & 3,19 & 83,25 \\
& Zona 2 & 4,79 & 125,01 \\
& Zona 3 & 9,16 & 239,07 \\
\multirow{4}{*}{ Krapyak - Ungaran } & Zona 1 & 3,19 & 83,25 \\
& Zona 2 & 4,79 & 125,01 \\
& Zona 3 & 11,67 & 304,58 \\
\multirow{2}{*}{ Krapyak - Srondol } & Zona 1 & 1,77 & 80,14 \\
& Zona 2 & 2,65 & 119,99 \\
\multirow{2}{*}{ Srondol - Krapyak } & Zona 3 & 4,28 & 193,8 \\
& Zona 1 & 1,77 & 80,14 \\
& Zona 2 & 2,65 & 119,99 \\
& Zona 3 & 4,28 & 193,8 \\
\hline
\end{tabular}

Jangkauan rele pada Tabel 1 dibandingkan dengan standar dari NPAG Alstom mengenai rele jarak.[6]

Tabel 2. Standar Setting Rele Jarak

\begin{tabular}{cc}
\hline Zona & Standar \\
\hline Zona 1 & $85 \%$ dari panjang saluran \\
Zona 2 min & $120 \%$ dari panjang saluran \\
Zona 2 max & Saluran yang diproteksi $+50 \%$ saluran terpendek didepannya \\
Zona 3 & 1,2 (saluran yang diproteksi + saluran terpanjang didepanya) \\
\hline
\end{tabular}

Tabel 3. Perbandingan Jangkauan Rele dengan Standar

\begin{tabular}{ccccc}
\hline Rele & Zona & Nilai Eksisting & Standar & Analisis \\
\hline \multirow{2}{*}{ Ungaran - } & Zona 1 & $83,25 \%$ & $85 \% L 1$ & Resetting \\
Krapyak & Zona 2 & $125,01 \%$ & $1,2 L 1$ & Resetting \\
& Zona 3 & $239,07 \%$ & $1,2(L 1+L 3)$ & Resetting \\
Krapyak - & Zona 1 & $83,25 \%$ & $85 \% L 1$ & Resetting \\
Ungaran & Zona 2 & $125,01 \%$ & $L 1+0,5 L 2$ & Resetting \\
& Zona 3 & $304,58 \%$ & $1,2(L 1+L 3)$ & Resetting \\
Krapyak - & Zona 1 & $80,14 \%$ & $85 \% L 1$ & Resetting \\
Srondol & Zona 2 & $119,99 \%$ & $L 1+0,5 L 2$ & Resetting \\
& Zona 3 & $193,8 \%$ & $1,2(L 1+L 3)$ & Resetting \\
Srondol - & Zona 1 & $80,14 \%$ & $85 \% L 1$ & Resetting \\
Krapyak & Zona 2 & $119,99 \%$ & $1,2 L 1$ & Resetting \\
& Zona 3 & $193,8 \%$ & $1,2(L 1+L 3)$ & Resetting \\
\hline
\end{tabular}

Tabel 3 menunjukkan bahwa nilai jangkauan eksisting belum memenuhi standar yang ditentukan. Untuk itu dilakukan perhitungan ulang dengan menggunakan standar berikut. [6]

\subsection{Perhitungan Ulang Setting Rele Jarak}

Contoh perhitungan diambil pada rele jarak Srondol Krapyak. Setting waktu pada rele jarak menurut standar IEEE yaitu zona 1 trip tanpa waktu tunda, zona 2 trip dengan waktu tunda (0,3 - 0,6 detik) dan disesuaikan juga dengan aplikasi di PLN. Setting waktu zona 2 pada PLN adalah 0,4 detik, serta zona 3 trip dengan waktu 1,6 detik sesuai kondisi di PLN.[7]

1. Perhitungan Zona 1

$\mathrm{L}_{1}=13,144 \mathrm{~km}$

Rasio CT $=600 / 1 \mathrm{~A}$

Rasio VT $=150 / 0,1 \mathrm{kV}$

$$
\begin{array}{rlr}
Z_{1} & =\sqrt{R^{2}+X^{2}} \\
& =\sqrt{0,137^{2}+0,397^{2}} & \\
& =0,42 \Omega & \\
Z_{L 1} & =Z_{1} \times L_{1} \\
& =0,42 \times 13,144 & \\
& =5.52 \Omega & \\
\text { Setting Impedansi Primer } & =0,85 Z_{L 1} \\
& =0,85 \times 5.52 \\
& =4,69 \Omega
\end{array}
$$

Setting Impedansi Sekunder
$=4,69 \times \frac{600 \times 0,1}{1 \times 150}$

$=1,876 \Omega$

2. Perhitungan Zona 2

$$
\begin{aligned}
\mathrm{L}_{2}= & 2,773 \mathrm{~km} \\
\mathrm{Z}_{2} & =\sqrt{R^{2}+X^{2}} \\
& =\sqrt{0,126^{2}+0,387^{2}} \\
& =0,4 \Omega \\
Z_{L 2} & =Z 2 \times L 2 \\
& =0,4 \times 2,773 \\
& =1,109 \Omega
\end{aligned}
$$

Setting Impedansi Primer $=1,2 Z_{L 1} / Z_{L 1}+0,5 Z_{L 2}$

$$
\begin{aligned}
& =1,2 Z_{L 1} \\
& =1,2 \times 5,52 \\
& =6,62 \Omega
\end{aligned}
$$

Setting Impedansi Sekunder

$$
\begin{aligned}
& =Z_{\text {primer }} \times \frac{C T_{\text {primer }} \times V T_{\text {sekunder }}}{C T_{\text {sekunder }} \times V T_{\text {primer }}} \\
& =6,62 \times \frac{600 \times 0,1}{1 \times 150} \\
& =2,648 \Omega
\end{aligned}
$$

3. Perhitungan Zona 3

$L_{3}=22,206 \mathrm{~km}$

$$
\begin{aligned}
Z_{3} & =\sqrt{R^{2}+X^{2}} \\
& =\sqrt{0,0685^{2}+0,2045^{2}} \\
& =0,215 \Omega \\
Z_{L 3} & =0,215 \times 22,206 \\
& =4,77 \Omega
\end{aligned}
$$

Setting Impedansi Primer $\quad=1,2\left(Z_{L 1}+Z_{L 3}\right)$

$$
\begin{aligned}
& =1,2(5,52+4,77) \\
& =1,2 \times 10,29 \\
& =12,34 \Omega
\end{aligned}
$$

Setting Impedansi Sekunder

$$
\begin{aligned}
& =Z_{\text {primer }} \times \frac{C T_{\text {primer }} \times V T_{\text {sekunder }}}{C T_{\text {sekunder }} \times V T_{\text {primer }}} \\
& =12,34 \times \frac{600 \times 0,1}{1 \times 150} \\
& =4,98 \Omega
\end{aligned}
$$

\section{Hasil dan Analisa}

\subsection{Perbandingan Jangkauan Rele}

Setelah dilakukan perhitungan ulang sesuai standar dari NPAG Alstom, didapatkan perbandingan jangkauan zona rele jarak seperti ditampilkan pada Tabel 4. 
Tabel 4. Perbandingan Jangkauan Rele

\begin{tabular}{ccccc}
\hline Rele & Zona & $\begin{array}{c}\text { Jangkauan } \\
\text { Eksisting (\%) }\end{array}$ & $\begin{array}{c}\text { Jangkauan } \\
\text { Resetting (\%) }\end{array}$ & $\begin{array}{c}\text { Standar } \\
(\%)\end{array}$ \\
\hline Ungaran & Zona 1 & 83,25 & 85 & $85 \% L_{1}$ \\
- Krapyak & Zona 2 & 125,01 & 120 & $1,2 L_{1}$ \\
& Zona 3 & 239,07 & 204,327 & $1,2\left(L_{1}+L_{3}\right)$ \\
Krapyak - & Zona 1 & 83,25 & 85 & $85 \% L_{1}$ \\
Ungaran & Zona 2 & 125,01 & 141,742 & $L_{1}+0,5 L_{2}$ \\
& Zona 3 & 304,58 & 220,227 & $1,2\left(L_{1}+L_{3}\right)$ \\
Krapyak - & Zona 1 & 80,14 & 85 & $85 \% L_{1}$ \\
Srondol & Zona 2 & 119,99 & 130 & $L 1+0,5 L_{2}$ \\
& Zona 3 & 193,8 & 193,35 & $1,2\left(L_{1}+L_{3}\right)$ \\
Srondol - & Zona 1 & 80,14 & 85 & $85 \% L_{1}$ \\
krapyak & Zona 2 & 119,99 & 120 & $1,2 L_{1}$ \\
& Zona 3 & 193,8 & 223,69 & $1,2\left(L_{1}+L_{3}\right)$ \\
\hline
\end{tabular}

Tabel 4 menunjukkan bahwa nilai jangkauan pada rele jarak setelah dilakukan perhitungan ulang sudah sesuai dengan standar.

\subsection{Perbandingan Koordinasi Rele Jarak}

1. Saluran Ungaran - Krapyak - Srondol

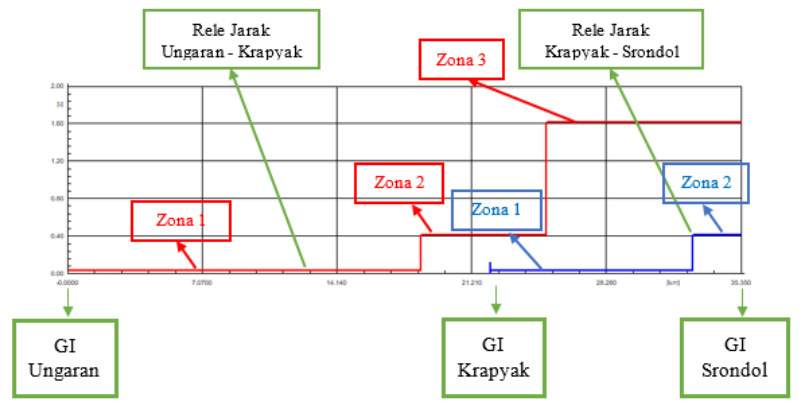

a. Kondisi Eksisting

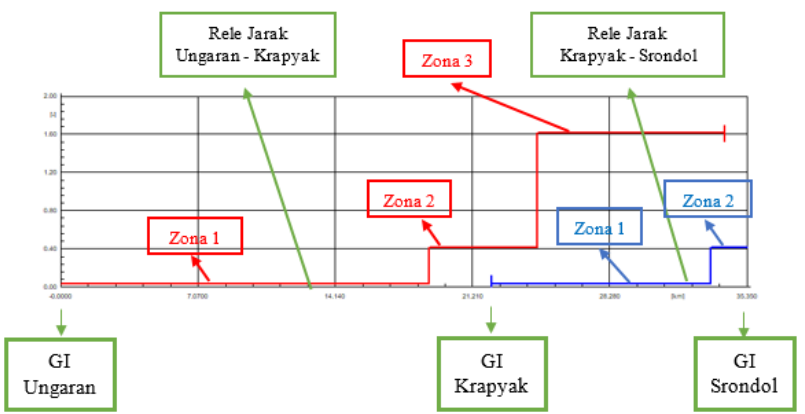

\section{b. Kondisi Resetting}

Gambar 3. Time - Distance Coordination saluran Ungaran Krapyak - Srondol (a) eksisting dan (b) resetting

Pada Gambar 3 dapat dilihat koordinasi rele jarak Ungaran - Krapyak dan Krapyak - Srondol pada kondisi eksisting dan resetting. Garis merah adalah diagram kerja rele jarak Ungaran - Krapyak dan garis biru adalah diagram kerja rele jarak Krapyak - Srondol. Dari Gambar 3 dapat dilihat bahwa rele jarak Ungaran - Krapyak dan Krapyak -
Srondol kondisi eksisting dan resetting telah terkoordinasi dengan baik. Hal ini dibuktikan dengan tidak adanya rele yang saling overlapping dalam kinerjanya.

2. Saluran Srondol - Krapyak - Ungaran

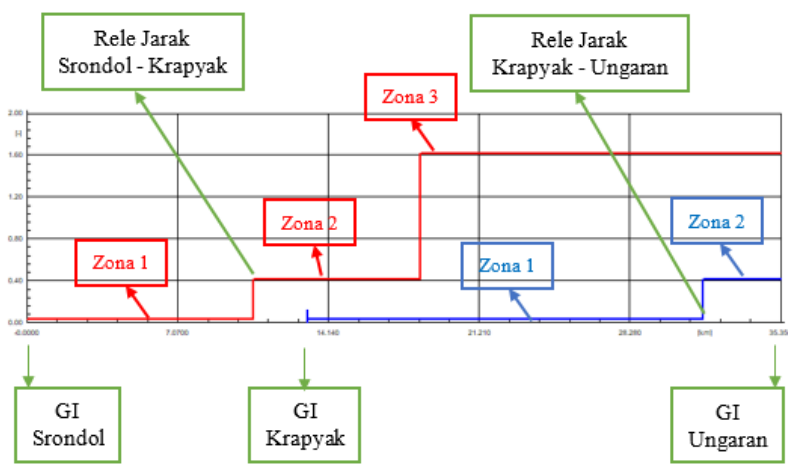

a. Kondisi Eksisting

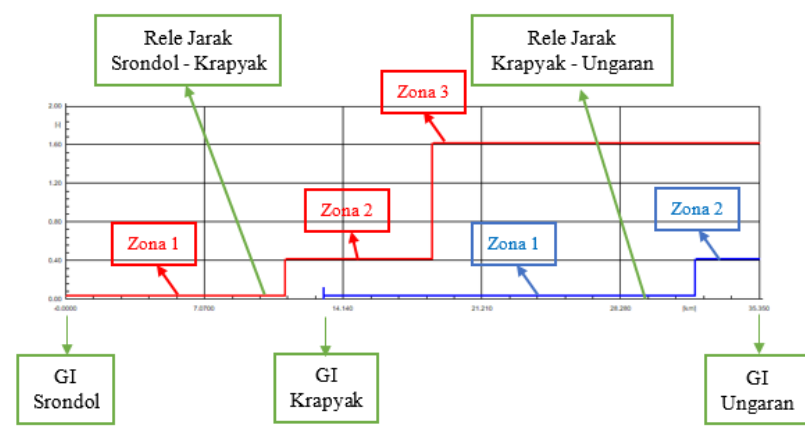

b. Kondisi Resetting

Gambar 4. Time - Distance Coordination saluran Srondol Krapyak - Ungaran (a) eksisting dan (b) resetting

Pada Gambar 4 dapat dilihat koordinasi rele jarak Ungaran - Krapyak dan Krapyak - Srondol pada kondisi eksisting dan resetting. Garis merah adalah diagram kerja rele jarak Ungaran - Krapyak dan garis biru adalah diagram kerja rele jarak Krapyak - Srondol. Dari Gambar 3 dapat dilihat bahwa rele jarak Ungaran - Krapyak dan Krapyak Srondol kondisi eksisting dan resetting telah terkoordinasi dengan baik. Hal ini dibuktikan dengan tidak adanya rele yang saling overlapping dalam kinerjanya.

\subsection{Skenario Gangguan}

Untuk melihat performa kerja masing-masing rele maka dilakukan simulasi gangguan hubung singkat berdasarkan skenario yang telah dirancang. Skenario gangguan yang akan disimulasikan berdasarkan data anomali yang didapatkan dari APP Semarang. Pada tahun 2017 hanya terjadi satu kali gangguan pada saluran Ungaran - Krapyak - Srondol, tepatnya di tower 38 saluran Krapyak - Srondol yang diakibatkan talut ambrol. Berdasarkan perhitungan yang telah dilakukan letak gangguan yang akan 
disimulasikan berada pada $\pm 84,39 \%$ dari saluran Srondol Krapyak. Agar dapat melihat kinerja rele dengan lebih baik, diberikan tambahan letak simulasi gangguan yaitu pada $\pm 61,35 \%$ pada saluran Krapyak - Srondol. Gangguan yang akan disimulasikan yaitu gangguan 2 fasa, 3 fasa, 1 fasa ke tanah, dan 2 fasa ke tanah. Berikut merupakan tabel skenario gangguan yang akan disimulasikan.

Tabel 5. Skenario Gangguan

\begin{tabular}{cccc}
\hline Skenario & Jenis Gangguan & Lokasi (\%) & Saluran \\
\hline \multirow{4}{*}{ Skenario 1 } & 3 fasa & 86,25 & \\
& 2 fasa & 83,37 & Srondol - Krapyak \\
& 1 fasa ke tanah & 84,39 & \\
& 2 fasa ke tanah & 87,13 & \\
Skenario 2 & 3 fasa & 70,24 & \\
& 2 fasa & 65,58 & Srondol - Krapyak \\
& 1 fasa ke tanah & 61,35 & \\
\hline & 2 fasa ke tanah & 67,11 & \\
\hline
\end{tabular}

3.4. Simulasi Gangguan

\subsubsection{Skenario Gangguan 1}

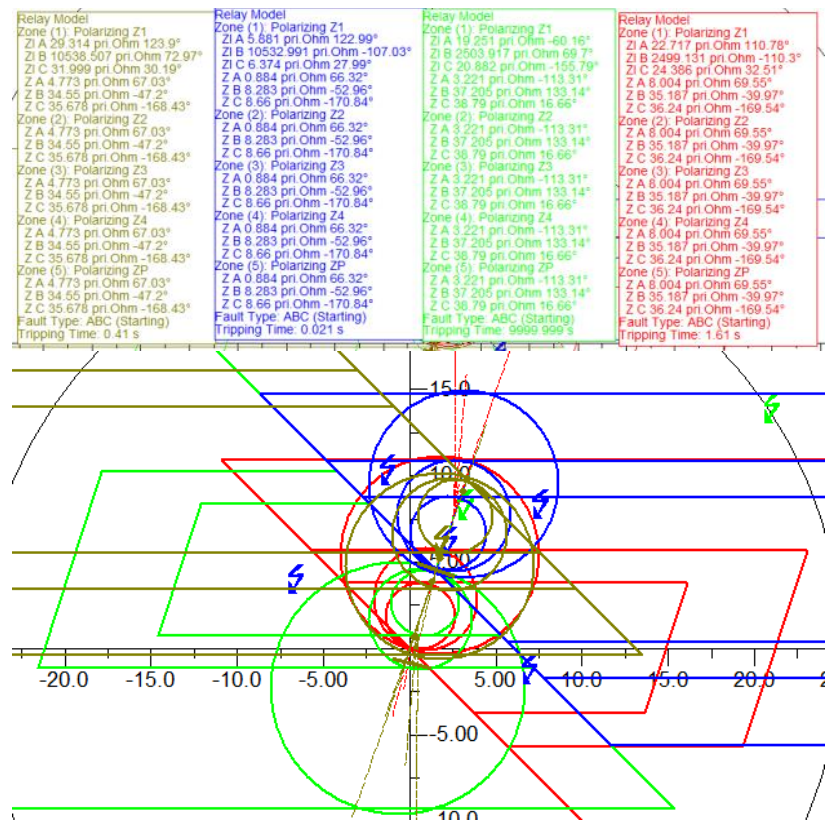

Gambar 5. Skenario Gangguan 1 Kondisi Eksisting

Berdasarkan Gambar 5 dapat dilihat saat terjadi gangguan 1 fasa ke tanah pada 84,39\% saluran Srondol - Krapyak, rele jarak Srondol - Krapyak membaca gangguan di zona 2 rele dengan waktu trip $0,41 \mathrm{~s}$. Hal ini menunjukkan bahwa kinerja rele kondisi eksisting belum sesuai dengan standar NPAG Alstom mengenai rele jarak. Berdasarkan standar dari NPAG, seharusnya zona 1 proteksi rele jarak mempunyai jangkauan $85 \%$ dari panjang saluran yang diproteksi dan waktu trip 0 s. Pada setting rele jarak Srondol - Krapyak kondisi eksisting, jangkauan zona 1 nya adalah $80,14 \%$. Hal inilah yang menyebabkan gangguan tersebut terbaca di zona 2 rele jarak. Rele jarak Krapyak Srondol membaca gangguan pada zona 1 proteksi rele dengan waktu trip $0,021 \mathrm{~s}$. Hal ini dikarenakan jarak antara gangguan dan rele jarak Krapyak - Srondol adalah 15,61\% dari panjang saluran, sedangkan setting zona 1 rele jarak Krapyak - Srondol adalah 80,14\% sehingga gangguan terbaca pada zona 1 rele. Rele jarak Krapyak - Ungaran tidak dapat membaca gangguan sehingga waktu trip nya 9999,9999. Hal ini dikarenakan rele jarak Krapyak Ungaran hanya bersifat forward, sehingga rele hanya bisa membaca gangguan yang berada di depannya. Gangguan yang diberikan berada di belakang rele sehingga rele tidak bekerja. Rele jarak Ungaran - Krapyak membaca gangguan pada zona 3 proteksi rele dengan waktu trip $1,61 \mathrm{~s}$.

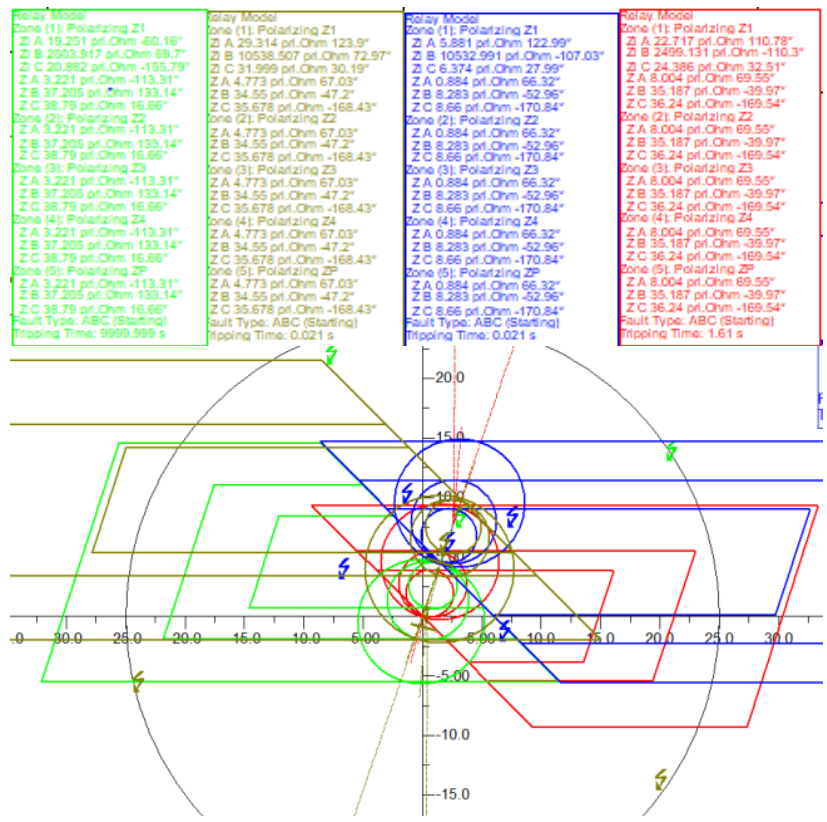

Gambar 6. Skenario Gangguan 1 Kondisi Resetting

Berdasarkan Tabel 6 dapat dilihat saat terjadi gangguan 1 fasa ke tanah pada 84,39\% saluran Srondol - Krapyak, rele jarak Srondol - Krapyak membaca gangguan di zona 1 rele dengan waktu trip 0,021s. Hal ini terjadi karena jangkauan zona 1 rele jarak Srondol - Krapyak nya adalah 85\% sehingga gangguan tersebut terbaca di zona 1 rele jarak. Rele jarak Krapyak - Srondol membaca gangguan pada zona 1 proteksi rele dengan waktu trip $0,021 \mathrm{~s}$. Hal ini dikarenakan jarak antara gangguan dan rele jarak Krapyak - Srondol adalah 15,61\% dari panjang saluran, sedangkan setting zona 1 rele jarak Krapyak - Srondol adalah 85\% sehingga gangguan terbaca pada zona 1 rele. Rele jarak Krapyak - Ungaran tidak dapat membaca gangguan sehingga waktu trip nya 9999,9999. Hal ini dikarenakan rele jarak Krapyak - Ungaran hanya bersifat forward, sehingga rele hanya bisa membaca gangguan yang berada di depannya. Gangguan yang diberikan berada di belakang rele sehingga rele tidak bekerja. Rele jarak Ungaran Krapyak membaca gangguan pada zona 3 proteksi rele dengan waktu trip $1,61 \mathrm{~s}$ 
Tabel 6 merupakan perbandingan waktu trip kondisi eksisting dan kondisi resetting hasil simulasi skenario gangguan 1

Tabel 6. Perbandingan Waktu Trip Rele

\begin{tabular}{cccc}
\hline \multirow{2}{*}{ Gangguan } & Rele & \multicolumn{2}{c}{ Waktu Trip (s ) } \\
& Eksisting & Resetting \\
\hline \multirow{2}{*}{1 fasa } & Srondol - Krapyak & 0,41 & 0,021 \\
ke tanah & Krapyak - Srondol & 0,021 & 0,021 \\
$84,39 \%$ & Krapyak - Ungaran & - & - \\
& Ungaran - Krapyak & 1,61 & 1,61 \\
2 fasa & Srondol - Krapyak & 0,41 & 0,41 \\
ke tanah & Krapyak - Srondol & 0,02 & 0,02 \\
$87,13 \%$ & Krapyak - Ungaran & - & - \\
& Ungaran - Krapyak & 1,61 & 1,61 \\
& Srondol - Krapyak & 0,41 & 0,02 \\
2 fasa & Krapyak - Srondol & 0,02 & 0,02 \\
$83,37 \%$ & Krapyak - Ungaran & - & - \\
& Ungaran - Krapyak & 1,61 & 1,61 \\
& Srondol - Krapyak & 0,41 & 0,41 \\
3 fasa & Krapyak - Srondol & 0,02 & 0,02 \\
$86,25 \%$ & Krapyak - Ungaran & - & - \\
& Ungaran - Krapyak & 1,61 & 1,61 \\
\hline
\end{tabular}

Tabel 6 menunjukkan bahwa pada skenario gangguan 1, terdapat rele jarak yang bekerja tidak sesuai dengan standar, yaitu rele jarak Srondol - Krapyak pada kondisi eksisting. Sedangkan pada kondisi resetting, waktu trip rele semuanya telah sesuai dengan standar yang digunakan.

\subsubsection{Skenario Gangguan 2}

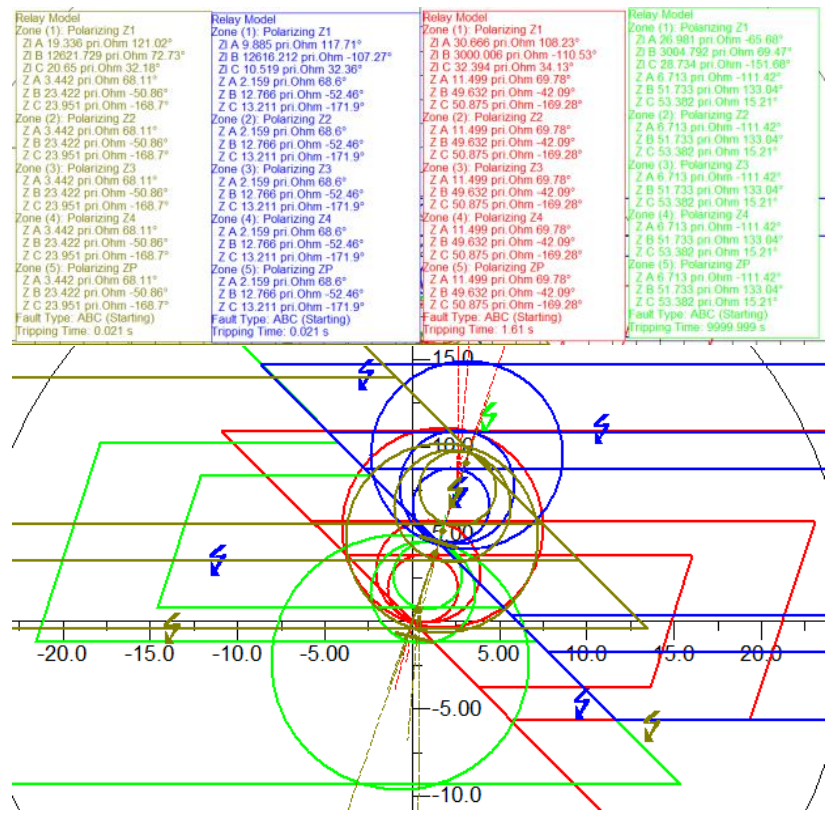

Gambar 7. Skenario Gangguan 2 Kondisi Eksisting

Berdasarkan Gambar 7 dapat dilihat saat terjadi gangguan 1 fasa ke tanah pada 61,35\% saluran Srondol - Krapyak, rele jarak Srondol - Krapyak membaca gangguan di zona 1 rele dengan waktu trip $0,021 \mathrm{~s}$. Hal ini terjadi karena jangkauan zona 1 rele jarak Srondol - Krapyak nya adalah $85 \%$ sehingga gangguan tersebut terbaca di zona 1 rele jarak. Rele jarak Krapyak - Srondol membaca gangguan pada zona 1 proteksi rele dengan waktu trip 0,021s. Hal ini dikarenakan jarak antara gangguan dan rele jarak Krapyak - Srondol adalah 38,65\% dari panjang saluran, sedangkan setting zona 1 rele jarak Krapyak - Srondol adalah 85\% sehingga gangguan terbaca pada zona 1 rele. Rele jarak Krapyak - Ungaran tidak dapat membaca gangguan sehingga waktu trip nya 9999,9999. Hal ini dikarenakan rele jarak Krapyak - Ungaran hanya bersifat forward, sehingga rele hanya bisa membaca gangguan yang berada di depannya. Gangguan yang diberikan berada di belakang rele sehingga rele tidak bekerja. Rele jarak Ungaran Krapyak tidak membaca gangguan sehingga waktu trip nya 9999,9999. Hal ini terjadi karena gangguan berada diluar jangkauan rele.

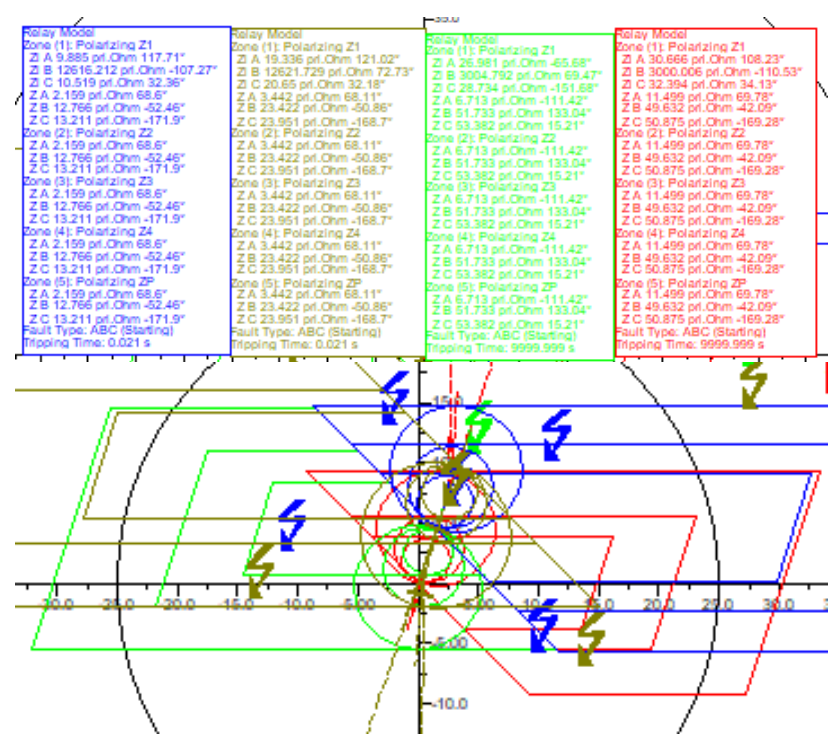

Gambar 8. Skenario Gangguan 2 Kondisi Resetting

Berdasarkan Gambar 8 dapat dilihat saat terjadi gangguan 1 fasa ke tanah pada 61,35\% saluran Srondol - Krapyak, rele jarak Srondol - Krapyak membaca gangguan di zona 1 rele dengan waktu trip 0,021s. Hal ini terjadi karena jangkauan zona 1 rele jarak Srondol - Krapyak nya adalah $85 \%$ sehingga gangguan tersebut terbaca di zona 1 rele jarak. Rele jarak Krapyak - Srondol membaca gangguan pada zona 1 proteksi rele dengan waktu trip 0,021s. Hal ini dikarenakan jarak antara gangguan dan rele jarak Krapyak - Srondol adalah 38,65\% dari panjang saluran, sedangkan setting zona 1 rele jarak Krapyak - Srondol adalah 85\% sehingga gangguan terbaca pada zona 1 rele. Rele jarak Krapyak - Ungaran tidak dapat membaca gangguan sehingga waktu trip nya 9999,9999. Hal ini dikarenakan rele jarak Krapyak - Ungaran hanya bersifat forward, sehingga rele hanya bisa membaca gangguan yang berada di depannya. Gangguan yang diberikan berada di belakang rele sehingga rele tidak bekerja. Rele jarak Ungaran Krapyak tidak membaca gangguan sehingga waktu trip nya 
9999,9999. Hal ini terjadi karena gangguan berada diluar jangkauan rele.

Tabel 7 merupakan perbandingan waktu trip kondisi eksisting dan kondisi resetting hasil simulasi skenario gangguan 2 .

\section{Tabel 7. Perbandingan Waktu Trip Rele}

\begin{tabular}{cccc}
\hline \multirow{2}{*}{ Gangguan } & Rele & \multicolumn{2}{c}{ Waktu Trip ( s ) } \\
& Eksisting & Resetting \\
\hline \multirow{2}{*}{1 fasa } & Srondol - Krapyak & 0,021 & 0,021 \\
ke tanah & Krapyak - Srondol & 0,021 & 0,021 \\
$61,35 \%$ & Krapyak - Ungaran & - & - \\
& Ungaran - Krapyak & 1,61 & - \\
2 fasa & Srondol - Krapyak & 0,02 & 0,02 \\
ke tanah & Krapyak - Srondol & 0,02 & 0,02 \\
$67,11 \%$ & Krapyak - Ungaran & - & - \\
& Ungaran - Krapyak & 1,61 & - \\
2 fasa & Srondol - Krapyak & 0,02 & 0,02 \\
$65,58 \%$ & Krapyak - Srondol & 0,02 & 0,02 \\
& Krapyak - Ungaran & - & - \\
& Ungaran - Krapyak & 1,61 & - \\
3 fasa & Srondol - Krapyak & 0,02 & 0,02 \\
$70,24 \%$ & Krapyak - Srondol & 0,02 & 0,02 \\
& Krapyak - Ungaran & - & - \\
& Ungaran - Krapyak & 1,61 & - \\
\hline
\end{tabular}

Tabel 7 menunjukkan bahwa pada skenario gangguan 2, rele jarak Srondol - Krapyak, Krapyak - Srondol dan Krapyak Ungaran menunjukkan kinerja baik pada kondisi eksisting maupun kondisi resetting. Pada rele jarak Ungaran - Krapyak pada kondisi eksisting gangguan masih terbaca, sedangkan pada kondisi resetting gangguan tidak terbaca. Hal ini dikarenakan pada kondisi eksisting setting zona 3 rele jarak Ungaran - Krapyak adalah $239,07 \%$ sedangkan setelah resetting jangkauan zona 3 nya menjadi $204,32 \%$.

\section{Kesimpulan}

Berdasarkan simulasi kinerja dan koordinasi yang telah dilakukan pada penelitian ini dapat diambil kesimpulan bahwa nilai jangkauan kondisi eksisting belum memenuhi standar dari NPAG mengenai rele jarak sehingga perlu dilakukan perhitungan ulang. Setelah dilakukan perhitungan ulang, nilai jangkauan rele jarak telah memenuhi standar. Berdasarkan simulasi koordinasi, koordinasi semua rele pada kondisi eksisting maupun resetting sudah benar ditandai dengan tidak adanya jangkauan rele yang saling overlapping. Berdasarkan simulasi pada skenario gangguan 1, terdapat rele jarak yang bekerja tidak sesuai dengan standar, yaitu rele jarak Srondol - Krapyak. Rele jarak Srondol - Krapyak membaca gangguan di zona 2 rele dengan waktu trip $0,41 \mathrm{~s}$. Hal ini dikarenakan pada kondisi eksisting setting zona 1 rele hanya mencapai $80,14 \%$.
Setelah dilakukan perhitungan ulang, rele membaca gangguan di zona 1 rele dengan waktu trip 0,02s. Hal ini dikarenakan pada kondisi resetting jangkauan zona 1 rele mencapai $85 \%$. Pada skenario gangguan 2, rele jarak Srondol - Krapyak, Krapyak - Srondol dan Krapyak Ungaran menunjukkan kinerja baik pada kondisi eksisting maupun kondisi resetting. Pada rele jarak Ungaran Krapyak pada kondisi eksisting gangguan masih terbaca, sedangkan pada kondisi resetting gangguan tidak terbaca. Hal ini dikarenakan pada kondisi eksisting setting zona 3 rele jarak Ungaran - Krapyak adalah 239,07\% sedangkan setelah resetting jangkauan zona 3 nya menjadi $204,32 \%$.

\section{Referensi}

[1]. W. D. Stevenson, Analisis Sistem Tenaga Listrik, 4th ed, Jakarta: Erlangga, 1996.

[2]. P. M. Anderson, POWER SYSTEM PROTECTION, Canada: WILEY-INTERSCIENCE, 1999.

[3]. R. Sudrajat, S. Saodah and Waluyo, "Analisis Penalaan Rele Jarak sebagai Proteksi Utama pada Saluran Udara Tegangan Tinggi 150kV Bandung Selatan - Cigereleng," J. Rela Elkomika, vol. ii, no. 1, pp. 36-48, 2014.

[4]. A. Jamaah. Evaluasi Setting Rele Jarak Gardu Induk Ungaran Jaringan 150kV arah Krapyak. ORBITH. 2014; 10(1): 82-89.

[5]. Supriana, Sang Kompyang. Studi Pengaruh Uprating Saluran Transmisi Tegangan Tinggi $150 \mathrm{kV}$ Terhadap Setting Rele Jarak Antara GI Kapal - GI Padang Sambian - GI Pesanggaran. Spektrum. 2014; 1(1): 59-64.

[6]. N. S. A. Bayu. Analisis Setting dan Koordinasi Rele Jarak pada GI 150kV Pandean Lamper arah Srondol. Transient. 2017; 6(1): 11-19.

[7]. ALSTOM, Network Protection \& Automation Guide, Stafford: Alstom Grid, 2011.

[8]. IEEE, IEEE Guide for Protective Relay Applications to Transmission Lines, New York: IEEE Standards Association, 2015. 